\section{OPEN ACCESS}

Edited by:

Francesco Fiorica,

Azienda UIss 9 Scaligera, Italy

Reviewed by:

Zexian Liu,

Sun Yat-sen University Cancer Center

(SYSUCC), China

Francesco Grignani,

University of Perugia, Italy

*Correspondence:

Ángeles Carlos-Reyes

reyes_cardoso@yahoo.com

Specialty section:

This article was submitted to Molecular and Cellular Oncology,

a section of the journal

Frontiers in Oncology

Received: 09 August 2019

Accepted: 28 November 2019

Published: 14 January 2020

Citation:

Hernández de la Cruz ON

López-González JS

García-Vázquez R, Salinas-Vera YM, Muñiz-Lino MA, Aguilar-Cazares D,

López-Camarillo $C$ and

Carlos-Reyes Á (2020) Regulation

Networks Driving Vasculogenic

Mimicry in Solid Tumors.

Front. Oncol. 9:1419.

doi: 10.3389/fonc.2019.01419

\title{
Regulation Networks Driving Vasculogenic Mimicry in Solid Tumors
}

\author{
Olga N. Hernández de la Cruz ${ }^{1}$, José Sullivan López-González², Raúl García-Vázquez", \\ Yarely M. Salinas-Vera ${ }^{1}$, Marcos A. Muñiz-Lino ${ }^{3}$, Dolores Aguilar-Cazares ${ }^{2}$, \\ César López-Camarillo ${ }^{1}$ and Ángeles Carlos-Reyes ${ }^{2 *}$
}

${ }^{1}$ Posgrado en Ciencias Genómicas, Universidad Autónoma de la Ciudad de México, Mexico, Mexico, ${ }^{2}$ Laboratorio de Cáncer de Pulmón, Instituto Nacional de Enfermedades Respiratorias "Ismael Cosío Villegas," Mexico, Mexico, ${ }^{3}$ Laboratorio de Patología y Medicina Bucal, Universidad Autónoma Metropolitana Unidad Xochimilco, Mexico, Mexico

Vasculogenic mimicry (VM) is a mechanism whereby cancer cells form microvascular structures similar to three-dimensional channels to provide nutrients and oxygen to tumors. Unlike angiogenesis, VM is characterized by the development of new patterned three-dimensional vascular-like structures independent of endothelial cells. This phenomenon has been observed in many types of highly aggressive solid tumors. The presence of VM has also been associated with increased resistance to chemotherapy, low survival, and poor prognosis. MicroRNAs (miRNAs) and long non-coding RNAs (IncRNAs) are non-coding RNAs that regulate gene expression at the post-transcriptional level through different pathways. In recent years, these tiny RNAs have been shown to be expressed aberrantly in different human malignancies, thus contributing to the hallmarks of cancer. In this context, miRNAs and IncRNAs can be excellent biomarkers for diagnosis, prognosis, and the prediction of response to therapy. In this review, we discuss the role that the tumor microenvironment and the epithelial-mesenchymal transition have in VM. We include an overview of the mechanisms of VM with examples of diverse types of tumors. Finally, we describe the regulation networks of IncRNAs-miRNAs and their clinical impact with the VM. Knowing the key genes that regulate and promote the development of VM in tumors with invasive, aggressive, and therapy-resistant phenotypes will facilitate the discovery of novel biomarker therapeutics against cancer as well as tools in the diagnosis and prognosis of patients.

Keywords: cancer, vasculogenic mimicry, microRNAs, long non-coding RNAs, epithelial-mesenchymal transition, tumor microenvironment

\section{INTRODUCTION}

Solid tumors can form new blood vessels through complex neovascularization mechanisms that include the following: (i) angiogenesis the development of new blood vessels by endothelial cells (ECs) from pre-existing vessels, (ii) vasculogenesis generated from EC precursors, (iii) intussusception the splitting of vessels through the insertion of tissue pillars, (iv) vessel co-option migration of tumor cells migrate along existing vasculature, (v) cancer stem cell (CSC) trans-differentiation whereby cancer cells trans-differentiate to ECs leading to the formation of 
blood vessels, and (vi) vasculogenic mimicry (VM) where the tumor cells mimic ECs and form blood vessel-like threedimensional channels (1-3).

In particular, VM can enhance cancer cell migration, invasion, and metastasis as well as increased resistance to therapies. VM has been documented in diverse solid tumors such as breast cancer, liver cancer, ovarian cancer, gastric cancer, prostate cancer, and melanoma $(4,5)$. During tumorigenesis, the tumor microenvironment plays a vital role in the formation of the tumor vasculature. Deficient blood-vessel perfusion, hypoxia due to low oxygen pressure, and low-nutrient availability in the microenvironment lead to angiogenesis, metastasis, and tumor cell survival $(6,7)$. Hypoxia is a master regulator of various transcription factors and signaling pathways during of the development of VM in solid tumors (8). On the other hand, microRNA (miRNAs) and long non-coding RNAs (lncRNAs) regulate the expression of genes and signaling pathways in diverse tumor types, which contributes to the cancer hallmarks like metastasis via VM formation (9). Here, we summarize the latest advances in VM regulation in solid tumors. We first overview the role of the tumor microenvironment and the epithelialmesenchymal transition (EMT) in VM from different types of tumors. We further described some mechanisms of VM. Finally, we detail the regulation by miRNAs and the regulation networks by lncRNAs-miRNAs as well as their clinical impact on VM.

\section{ROLE OF TUMOR MICROENVIRONMENT AND THE EMT IN THE DEVELOPMENT OF VM}

The tumor microenvironment comprises the vasculature (blood vessels), extracellular matrix, stromal cells, immune cells, and signaling molecules. Poor blood-vessel perfusion in the tumor microenvironment is due to acidic $\mathrm{pH}$, low nutrient levels, and hypoxia due to low oxygen pressure $(10,11)$. These aspects cause an imbalance in the angiogenic and anti-angiogenics factors that favor the invasion and metastasis of tumor cells. Tumor cell adaptation to the hypoxic microenvironment favors sustained angiogenesis (12). In particular, acidic $\mathrm{pH}$ and hypoxia are important factors for remodeling EMC. The acidic $\mathrm{pH}$ in solid tumors is due to the production of lactic acid during the fermentative metabolism produced by the high expression of $\mathrm{Na}+/ \mathrm{H}+$ exchangers (NHE1), isoforms of anion exchangers, $\mathrm{Na} / \mathrm{HCO}_{3}^{-}$co-transporters, $\mathrm{H}+$ /ATPases, carbonic anhydrase IX isoform, monocarboxylate transporters, and the vacuolar ATPase. The released proton $(\mathrm{H}+)$ acidifies the tumor microenvironment and diffuses toward the stroma increasing the tumor survival, proliferation, and angiogenesis (13).

A crucial event in the development, progression, and metastasis of malignant tumors is neovascularization. It supplies growth factors, nutrients, and oxygen that alter the vascularization of the tumor including sustained angiogenesis (3). A new mechanism of neovascularization is VM that leads to the formation of blood vessels by the tumor cells themselves independently of ECs. VM is characterized by the deregulation of genes such as vimentin, cadherins, and metalloproteases and can be detected by double PAS/CD31 staining $(5,14)$. Tumors that show VM are highly aggressive and metastatic invasive phenotypes that are resistant to therapies (15). VM is promoted by the hypoxic tumor microenvironment, acidic $\mathrm{pH}$, low nutrient levels, and the EMT (16).

Several studies report that the hypoxic tumor microenvironment regulates different transcription factors mediated by HIF-1 $\alpha$. These factors induce VM development as well as the regulation of epithelial markers that favor the EMT in different solid tumors (Figure 1 and see Table 1) (16-42).

We show some reports of the role of the tumor microenvironment and EMT in the VM. In melanoma, hypoxia activates MMP-2 and MMP-9 expression promoting invasion to adjacent tissue. There is also deficient blood perfusion due to HIF- $1 \alpha$ high expression (43). In addition, an increase in HIF- $1 \alpha$ causes high expression of VEGF that facilitates the formation of VM. In a different study, the authors found that melanoma cells showed an increase in $\mathrm{Bcl}-2$ expression promoting the formation of three-dimensional tubular structures via the VE-cadherin up-regulation mediated by Bcl-2 (44).

Ovarian cancer includes high expression levels of human chorionic gonadotropin and HIF- $1 \alpha$, which contribute to cell proliferation and tumor growth. They also lead to VM via the luteinizing hormone receptor (45-47). Only 25\% of ovarian cancer biopsies are positive for VM, which correlates with hypoxia and EMT and is due to the high expression levels of HIF-1 $\alpha$, vimentin, VE-cadherin, Twist1, and Slug (21). These factors decrease E-cadherin expression. A hypoxic environment in breast cancer can increase the levels of HIF-1 $\alpha$, VE-cadherin, MMP-9, Cdc42, EGFR, p-Akt, and p-mTOR to promote the development of VM via the HIF-1 $\alpha$ /VE-cadherin/MMP-9, MMP-2 signaling pathway (48). In the colorectal cancer HCT116 cell line, hypoxia-induced development of $\mathrm{VM}$ is due to an increase in the zinc finger E-box binding homeobox 1 (ZEB1) and HIF- $1 \alpha$ as well as with high vimentin expression and loss of E-cadherin expression in EMT (25).

The relationship between Bcl-2/Twist1 and Bcl-2-Bmil promotes EMT and development of VM through loss expression of E-cadherin and increased vimentin expression in hepatic cancer cells. VM is also caused by the translocation of Twist 1 to the nucleus via Bcl-2 due to hypoxia (49-51). In biopsies of hepatic cancer, high expression levels of Notch1 and Hes1 were associated with VM. In hepatic cancer HepG2 and MHCC97-H cell lines, the Notch1 expression was higher in HepG2 favoring invasiveness by inducing the EMT through an increase in vimentin and loss of E-cadherin expression. These events are mediated by stimulation of TGF- $\beta 1$ (30).

Glioma biopsies have increased expression in HIF-1 $\alpha$, MIF, and CXCR4. This has been observed in hypoxic regions of the tumor and is associated with VM development. In U87 and U251 glioma cell lines, high expression of MIF and CXCR4 promoted EMT and VM formation. In in vivo assays, MIF induces VM through the CXCR4-AKT-signaling pathway (35). In other reports, the glioma cell line SHG-44 transfected with pEGFP-Cl-LRIG1 and overexpressing LRIG1 inhibits VM promoted by hypoxia as well as migration, invasion, and proliferation. In addition, LRIG1 expression repressed signaling 


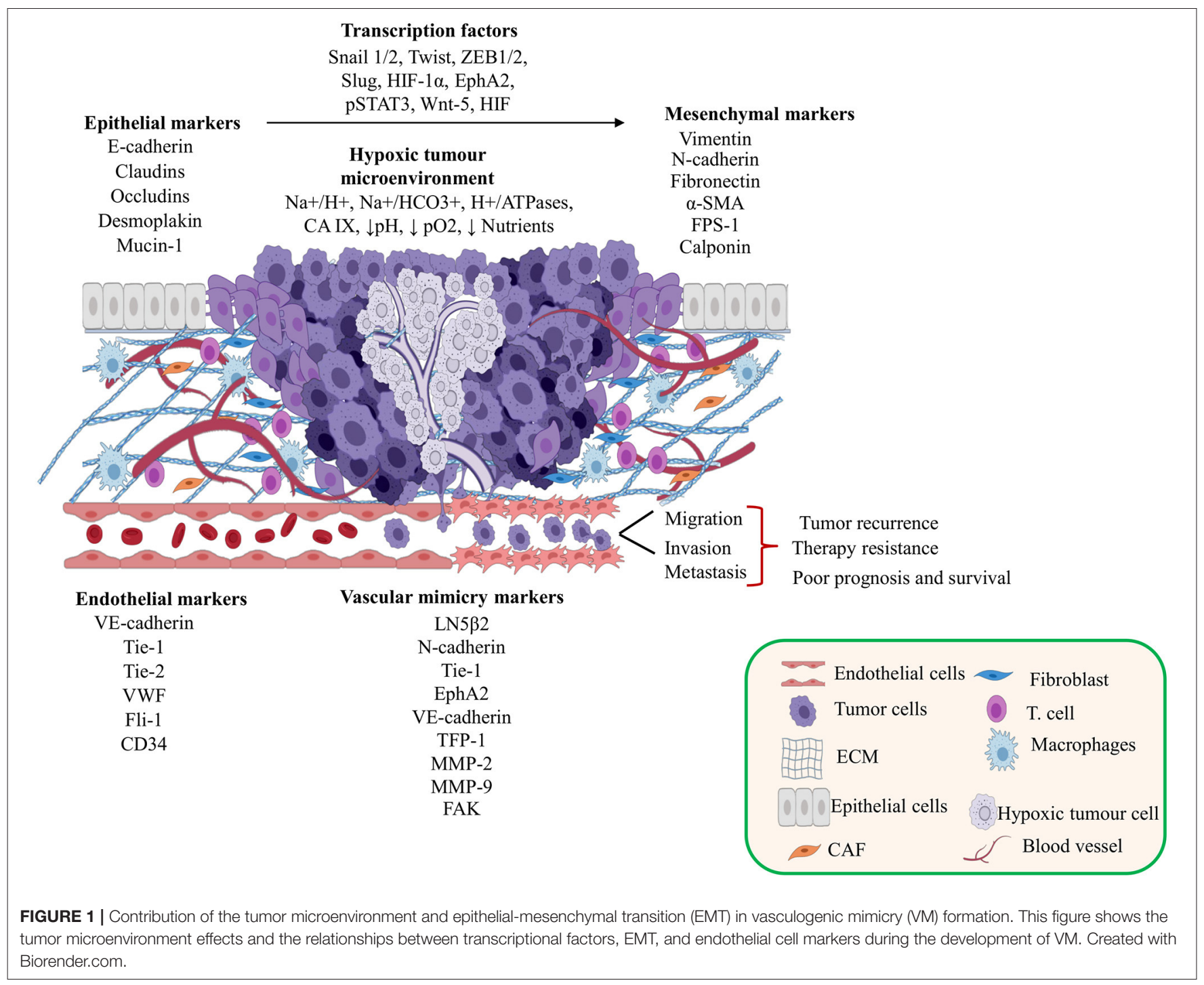

of the EGFR/PI3K/AKT and EMT through an increase in Ecadherin and low vimentin expressions (52).

In melanoma, LRIG1 shows the same effects as glioma, but these are mediated by blocking via EGFR/ERK signaling (34). SACC-83 and SACC-LM salivary adenoid cystic carcinoma cell lines (SACC cells) have VM due to growth factors such as VEGFA that promote the development of VM mediated by hypoxia favoring migration and invasion as well as the EMT. Furthermore, the self-renewal capacity of SAAC-LM cells was due to the acquisition of the stem cell phenotype through VEGFA over-expression as well as an increase in the expression of $\mathrm{N}$-cadherin, vimentin, CD44, and ALDH1 and loss of E-cadherin. These authors reported that only $26.3 \%$ of biopsies showed channel formation typical of VM. This phenomenon is related to HIF- $1 \alpha$ and VEGFA expression (53). High expression levels of signal transducer and activator of transcription-3 (STAT3), p-STAT3, and HIF-1 $\alpha$ in gastric cancer tissues for positive VM were associated with metastasis, degree of differentiation, and prognosis (54). On the other hand, esophageal squamous cancer cell lines Eca 109 and TE13 increased HIF- $1 \alpha$ expression in hypoxic microenvironments. This promoted the VE-cadherin expression and led to VM development through the regulation of EphA2 and laminin subunit 5 gamma-2 (LN5 $\gamma 2$ ) expressions (55).

The EMT promotes the VM induced by hypoxia through the regulation of different transcriptional factors that promote the most aggressive, invasive, and metastatic phenotypes. These phenotypes are frequently therapy resistant with high recurrence.

\section{MECHANISMS OF VM IN HUMAN CANCERS}

Many studies have reported the participation of several transcription factors impacting diverse signaling pathways including EphA2, VE-cadherin, VEGFR2 (Flk-1), Rho, and integrins. These pathways regulate the VM development (Figure 2). In this review, we summarize some mechanisms related to the development of VM in solid tumors. Some of 
TABLE 1 | Molecular factors that promote the EMT and VM in solid tumors.

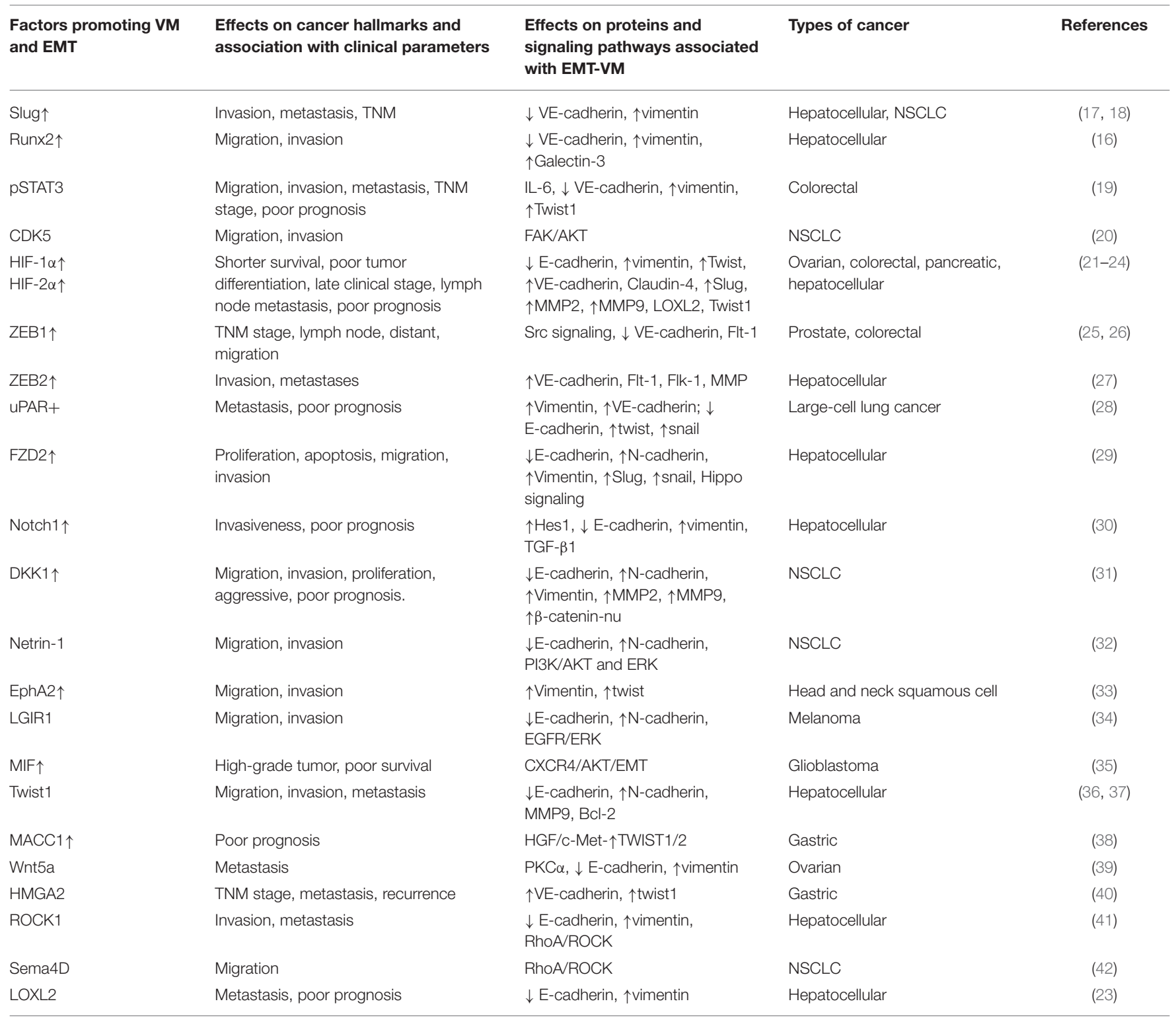

$\uparrow$ High expression, $\downarrow$ low expression. EMT, epithelial-mesenchymal transition; VM, vascular mimicry; NSCLC, non-small cell lung cancer.

these are driven by different receptors like the Eph receptor tyrosine kinases and the ephrin ligands that have been extensively implicated in carcinogenesis (56).

EphA1 and EphA2 are the most well-characterized molecules in solid tumors. They are implicated in VM formation and angiogenesis. High invasive MUM-2B melanoma cell line develops vascular pattern networks that are PAS positive. Such networks are associated with high expression and phosphorylation of EphA2 (57). Recent studies in vivo and in vitro in prostate cancer showed that VM development was associated with high expression of EphA2 and PI3K. PI3K/AKT regulates the activity of EphA2 through phosphorylation at Ser897 position (58). In addition, Yeo and coworkers showed that fetal bovine serum at $1-5 \%$ induced VM formation in prostate cancer PC-3 cells as well as phosphorylation of EphA2. This also increased the expression of VE-cadherin and Twist and activated AKT signaling. These changes were accompanied by an increase in MMP-2 and LN5 $\gamma 2$ protein levels (59). More experiments are needed to analyze whether cellular stress caused by reduced concentrations of fetal calf serum induced the development of VM.

Liang and coworkers found that Rictor, a component of mTOR2 signaling highly expressed in melanoma, was related to the presence of VM. These were associated with poor patient survival. The authors showed that VM was regulated through an increased activity of AKT-MMP-2/9 signaling and phosphorylation of AKT at Ser473 and Thr308 mediated by Rictor (60). In breast cancer, overexpression of $\mathrm{B}$ and $\mathrm{C}$ isoforms 


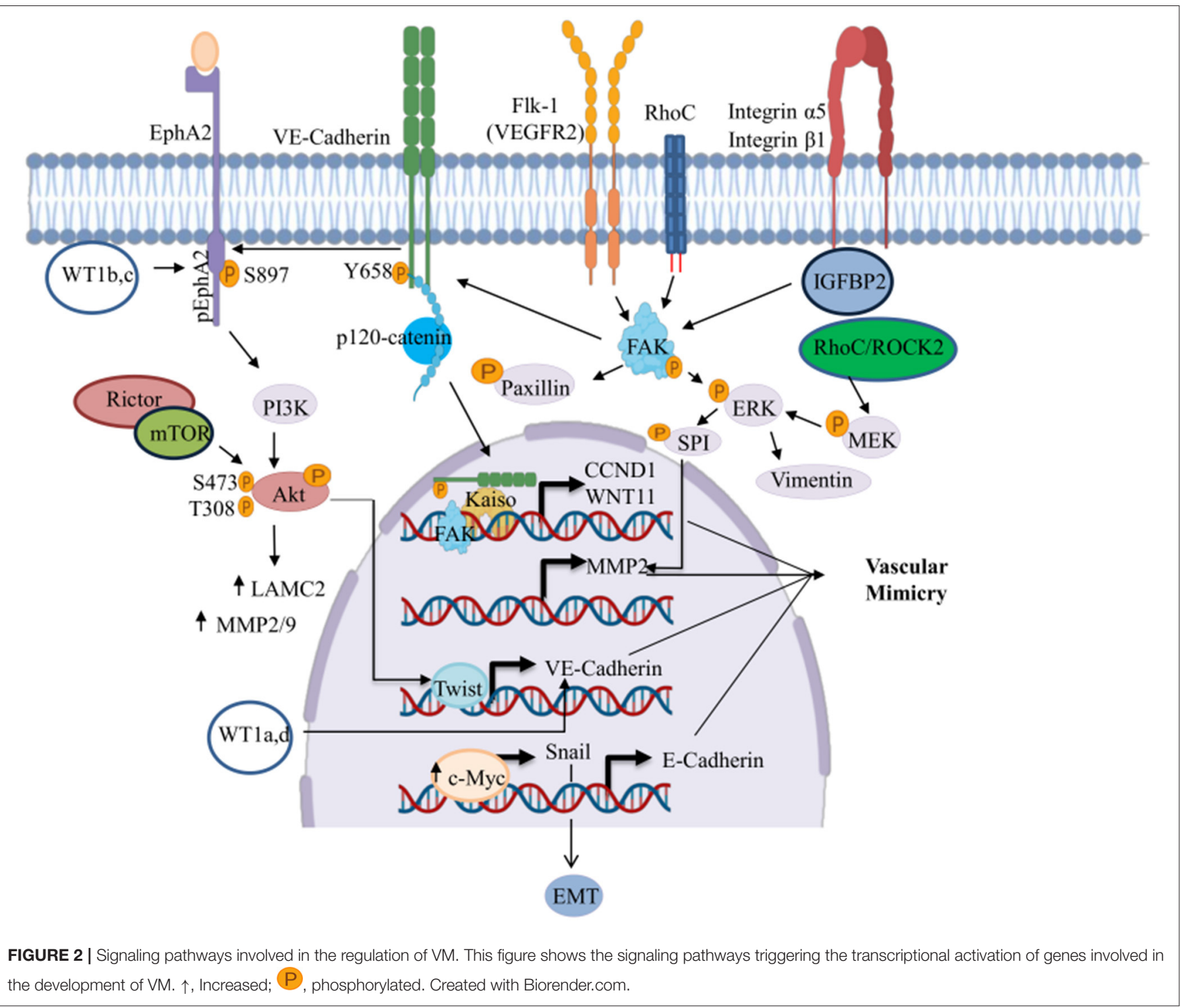

of WT1 promoted VM development due to the EphA2/ $\beta$ catenin/vimentin signaling pathway (61). In contrast, highly aggressive gallbladder carcinomas develop VM mediated by high levels of MMP-2 and MT1-MMP the overexpression of EphA2, FAK/PI3K, and LN-5 $\gamma 2$ signaling pathways, and via Paxillin-P signaling in vitro and in vivo (62).

Another mechanism for promotion of VM is mediated by VE-cadherin, one of the major endothelial adhesion molecule controlling intercellular junctions for blood vessel formation. This occurs via vascular endothelial growth factor receptor (VEGFR) function (63). Delgado-Bellido and coworkers found that malignant melanoma cells show constitutive expression of phosphorylated VE-cadherin at the Y658 position and forms a complex with p120-catenin and the transcriptional repressor kaiso. The high expression of nuclear phosphorylated VE-cadherin activated kaiso-dependent genes CCDN1 and WNT11 that increase the VM formation (64). Other study in melanoma showed that the c-Myc proto-oncogene was highly expressed in metastatic melanoma and induced VM through Snail activation inducing EMT by TGF- $\beta /$ Snail/E-cadherin signaling pathways. $\mathrm{c}-\mathrm{Myc}$ increases Bax expression causing a decrease in the $\mathrm{Bcl} 2 / \mathrm{Bax}$ ratio through bilinearly patterned programmed cell necrosis. Necrosis forms empty spaces similar to blood vessels that serve as a support for VM formation under severe hypoxia (65). On the other hand, HER2-positive tumors showed high VM formation via VE-cadherin regulation (66).

Integrins are cellular adhesion receptors for cell attachment to the extracellular matrix. They transmit signals between cells and microenvironment. Integrins have multiple functions in cancer from initiation through metastasis, and they have been implicated in VM in various cancer types (67). In glioblastoma, Liu and coworkers analyzed tumors with VM and found a positive correlation between high levels of insulin-like growth factor-binding protein 2 (IGFBP2) and CD144/MMP-2 
expression. They further found that overexpression of IGFBP2 increased tubule network formation through activation of CD144 and MMP-2, which was mediated by the binding of IGFBP2 to integrin $\alpha 5 / \beta 1$ and activation of the FAK/ERK/SPI pathway (68). Another report in glioblastoma multiforme showed that the presence of tumor-associated macrophages with M2 phenotype 2 infiltrating the VM-positive tissue area was associated with high levels of cyclooxygenase-2 (COX-2). Co-cultures of the U87 cell line with M2 macrophages activated by interleukin4 promoted VM development through the prostaglandin E2/EP1/PKC pathway with high COX-2 and $\alpha$-SMA expression and low VE-cadherin expression (69). In contrast, breast cancer cell lines that overexpress COX-2 vascular channels were also reported; this event was inhibited by COX inhibition (celecoxib) or siRNAs and was restored upon addition of exogenous prostaglandin E2 (70).

VEGF signaling via tyrosine kinase receptor VEGF receptor 2 (Flk-1) has a critical role in tumor angiogenesis and promotion of VM in cancer $(71,72)$. Blood vessels detected in the VM of glioblastoma cells are integrated by mural cell-lined vasculature. In glioblastoma, U87 and GDSC cell lines promoted VM formation. This formation was mediated by high expression of Flk-1 and VE-cadherin. Suppression of Flk-1 activity with SU1498 inhibitors in turn inhibits VM formation as well as FAK and ERK1/2 signaling pathways (73).

RhoC (Ras homolog gene family member C) regulates cytoskeletal organization and affects the motility of cancer cells favoring invasion and metastasis as well as progression and VM formation (74). In hepatocellular carcinoma (HCC), vascular channels were formed, and these vessels were associated with RhoC FAK/Paxillin signaling regulation as well as with high expression of RhoC/ROCK2, VE-cadherin, and MMP2 mediated by ERK/MMPs signaling (75).

\section{CSCs AND VM}

CSCs are a subgroup of tumor cells that are multipotent with the capacity for self-renewal and differentiation as well as phenotypic and functional features of stem cells. In recent years, several reports have shown the role of CSC in the development of VM; they can form vascular-like structures that mimic embryonic vascular network patterns that are pivotal in tumor progression (76). For instance, in colorectal cancer, the Wnt $/ \beta$-catenin pathway can induce VM formation through high Wnt3 and low $\beta$-catenin expressions. This pathway can also increase the expression of VEGFR2 and VE-cadherin. Thus, the $\mathrm{Wnt} / \beta$-catenin activation favors the acquisition of endothelial phenotypes (77).

The glioblastomas undergo trans-differentiation into CD133positive vascular ECs that promote the formation of glioma stem-like cells that can initiate the development of VM through VEGFR2 and VE-cadherin (72). In HCC, the Frizzled-2 gene (FZD2) induces proliferation, migration, and invasion due to its high expression. HCC also has decreased E-cadherin expression and increased N-cadherin, Snail, and Slug expressions. This promotes the EMT and VM formation. FZD2 also regulates the transcription factors Nanog and SOX2 in pluripotent cells favoring stemness. Moreover, the enrichment analysis of DEGs showed that FZD2 has a close relationship to the Hippo pathway mediated by the activity of YAP and TAZ (29). The tumorigenic growth of melanoma is shaped by stem-like cells. This cancer can grow to form spheroid cells that generate laminin networks similar to VM. These laminin networks have high expression of VE-cadherin, VEGFR-1, and nestin stem cell-associated biomarkers (78). These reports demonstrate that subpopulations of CSCs can transdifferentiate, and they contribute to development of VM in solid tumors.

\section{REGULATION OF VM BY MIRNAs IN SOLID TUMORS}

miRNAs are post-transcriptional regulators of gene expression; they participate in degradation and/or inhibition of translation of their target genes (79). The alteration of the expression of multiple miRNAs has been reported in diverse types of solid tumors, and they act as oncogenes or tumor suppressors (80). Dysregulation of both groups correlates with diverse biological processes such as proliferation, invasion, migration, and VM in human cancer (see Table 2) (81-102). An important signaling pathway is VE-cadherin; it is one of the first factors identified as a regulator of VM. Liu and coworkers recently demonstrated the low expression of miR-27b in ovarian cancer cells. Restoring miR-27b expression in ovarian Hey1B and ES2 cancer cell lines significantly decreased intracellular VE-cadherin expression. This inhibits invasion, metastasis, and VM caused by the direct binding of miR-27b to the $3^{\prime}$-UTR region of VE-cadherin (89). In HCC cell lines, the miR-27a-3p and miR-17 were downregulated and associated with high $\mathrm{Bcl}-2$ expression. The VEcadherin, MMP-2, Twist1, HIF-1 $\alpha$, and VEGFA also lead to VM. In hepatic tumors, these genes were associated with poor prognosis of patients. Moreover, miR-27a-3p functions as a tumor suppressor for invasion and metastasis and is mediated by downregulation of VE-cadherin and $\operatorname{EMT}(96,97)$. The miRNAs also regulate the EMT and facilitate the development of capillarylike structures in the tumors. They adopt invasive and metastatic properties. There was a decrease in miR-186 expression levels in P69 and M12 prostate cancer cell lines and tissues of patients with metastatic prostate cancer. The restoration of miR-186 suppresses cell motility, invasion, colony formation, and threedimensional culture growth, and inhibits the EMT through the negative modulation of Twist1 transcription factor (100). miR-124 in cervical cancer induced the suppression of the EMT process and decreased migration, invasion, and VM due to its specific interaction with $3^{\prime}$ UTR of the angiomotin like 1 (AmotL1) protein that regulates cell migration related to angiomotin $(87,102)$.

Several reports have shown that Eph2A expression is regulated by different miRNAs. In glioma and glioblastomas cell lines, overexpression of miR-26b and miR-141 inhibited VM formation through their specific binding with the Eph2A 3'-UTR region. Also, both miRNAs regulate cell proliferation, migration, and invasion $(92,95)$. Ovarian cancer has a decrease in the expression 
TABLE 2 | Modulation of VM by microRNAs (miRNAs).

\begin{tabular}{|c|c|c|c|c|}
\hline miRNAs & Targets & Biological function & Cancer type & References \\
\hline $\begin{array}{l}\text { mir-200C, mir-183, mir-96, mir-182 } \\
\text { mir-299-5P } \\
\text { mir-125a, Let-7e } \\
\text { mir-193b } \\
\text { miR-204 }\end{array}$ & $\begin{array}{l}\text { ZEB-1 } \\
\text { OPN } \\
\text { IL-6, IL-6R,STAT3 } \\
\text { DDAH1 } \\
\text { PI3K, c-SRC, FAK }\end{array}$ & $\begin{array}{l}\text { Inhibit VM, increased proliferation, chemotherapy, } \\
\text { poor prognosis }\end{array}$ & Breast & $\begin{array}{l}(82) \\
(83) \\
(84) \\
(85) \\
(86)\end{array}$ \\
\hline mir-124 & AmotL1, STAT3 & Inhibit migration, invasion, EMT, VM & Cervical, oral & $(87,102)$ \\
\hline $\begin{array}{l}\text { mir-200a } \\
\text { mir-27b } \\
\text { miR-765 }\end{array}$ & $\begin{array}{l}\text { EphA2 } \\
\text { VE-cadherin } \\
\text { VEGFA, AKT1, SRC- } \alpha\end{array}$ & Poor survival, inhibit VM, Inhibit migration, invasion & Ovarian & $\begin{array}{l}(88) \\
(89) \\
(90)\end{array}$ \\
\hline $\begin{array}{l}\text { miR-9 } \\
\text { mir-26b } \\
\text { miR-Let-7f } \\
\text { mir-584-3p } \\
\text { miR-141 }\end{array}$ & $\begin{array}{l}\text { STMN1 } \\
\text { EphA2 } \\
\text { POSTN } \\
\text { ROCK1 } \\
\text { EphA2 }\end{array}$ & $\begin{array}{l}\text { Decreased tumor growth, VM, } \\
\text { glioma grades II, III and IV, prognostic indicator, } \\
\text { proliferation, migration, invasion }\end{array}$ & Glioma & $\begin{array}{l}(91) \\
(92) \\
(93) \\
(94) \\
(95)\end{array}$ \\
\hline $\begin{array}{l}\operatorname{miR}-27 a \\
\text { miR-17 } \\
\text { miR-27a-3p } \\
\text { mir-101 } \\
\text { mir-29b }\end{array}$ & $\begin{array}{l}\text { CDH5, SMAD2, TGFBR1, } \\
\text { VEGF } \\
\text { VEGF, HIF1A, MMP2 } \\
\text { VE-cadherin } \\
\text { TGF-BR1,Smad2 SDF1 } \\
\text { IL-6, STAT3, MMP-2 }\end{array}$ & $\begin{array}{l}\text { Poor prognosis, represses early metastasis, } \\
\text { EMT, VM }\end{array}$ & Hepatocellular & $\begin{array}{l}(96) \\
(97) \\
(98) \\
(99)\end{array}$ \\
\hline miR-186 & TWIST1 & $\begin{array}{l}\text { Inhibit tumor progression, invasion, colony } \\
\text { formation, EMT }\end{array}$ & Prostate & $(100)$ \\
\hline miR-490-3p & TR4, Vimentin & Promote metastasis, VM & ccRCC & $(81)$ \\
\hline miR-409-3p & ANG & $\begin{array}{l}\text { Suppresses proliferation, tumor growth, metastasis, } \\
\text { VM }\end{array}$ & Fibrosarcoma & $(101)$ \\
\hline
\end{tabular}

levels of miR-200a that induce VM development. The restoration of miR-200a inhibits VM through modulation of the expression of EphA2. Also, low miR-200a expression has been associated with tumor grade and metastasis (88).

VEGF expression has been detected in hypoxic environments, and its secretion by tumor cells plays a crucial role in the tumor angiogenesis and VM formation $(71,72)$. Salinas-Vera et al. reported that miR-765 decreased VEGF expression after hypoxic conditions in ovarian cancer. Restoration in SKOV3 cells resulted in a significant inhibition of VM suggesting that miR-765 coordinates VM formation through modulation of the VEGFA/AKT1/SRC- $\alpha$ signaling pathway (90). The same group reported that miR-204 reduced the expression and phosphorylation of 13 proteins involved in the PI3K/AKT, RAF1/MAPK, VEGF, and FAK/SRC signaling pathways in MDAMB-231 breast cancer cell line. These pathways impact VM development; its restoration repressed the VM formation and regulated the PI3K/AKT signaling pathway through its specific interaction with PI3K and SRC (86).

Multicellular spheroids derived from MCF-7, MCF10AT, and MCF10DCIS cell lines reproduce the architecture and tumor physiology observed in vivo. These models show high expression of osteopontin (OPN) oncoprotein via downregulation of miR299-5p leading to vascular structures similar to VM (83). However, more studies are required in other type of tumors to correlate whether multicellular spheroids are linked with VM.

In gliomas, the expression decrease of miR-584-3p has been related with VM formation. The restoration of this miRNA expression inhibits VM formation in vitro through direct binding with the $3^{\prime}$-UTR region of ROCK1 (94). In this same tumor,
miR-Let-7f overexpression suppresses VM by repression of periostin (POSTN) that can induce migration of the cells. Overexpression of miR-9 a tissue-specific miRNA in the central nervous system increases apoptosis, suppresses tumor volume, and decreases cell proliferation and migration as well as VM formation in vivo and in vitro through negative regulation of the oncoprotein Stathmin (STMN1) $(91,93)$.

These studies show the essential role of the miRNAs in regulating the $\mathrm{VM}$, in addition to other signaling pathways related to hallmarks cancer as cell proliferation, invasion, migration, and sustained angiogenesis in which new microcirculation process are implicated in therapy resistance and tumor recurrence.

\section{IncRNAs-miRNAs-mRNAs REGULATION NETWORKS OF THE VM AND THEIR CLINICAL RELATIONSHIP}

lncRNAs are a heterogeneous group of RNA molecules longer than 200 nucleotides. They have a dynamic role in the transcriptional and translational regulation of key genes in several diseases including of cancer. Their aberrant lncRNAs expression in the tumorigenesis contributes to metastasis, progression, and patient survival, as well as with VM development (103). The lncRNAs act as a competitive endogenous RNA. They change the expression transcriptional by competing for specific miRNAs binding sites altering their interaction. The regulation of lncRNAs in the miRNAs forms a complex regulatory network of lncRNAs-miRNAs-mRNAs 


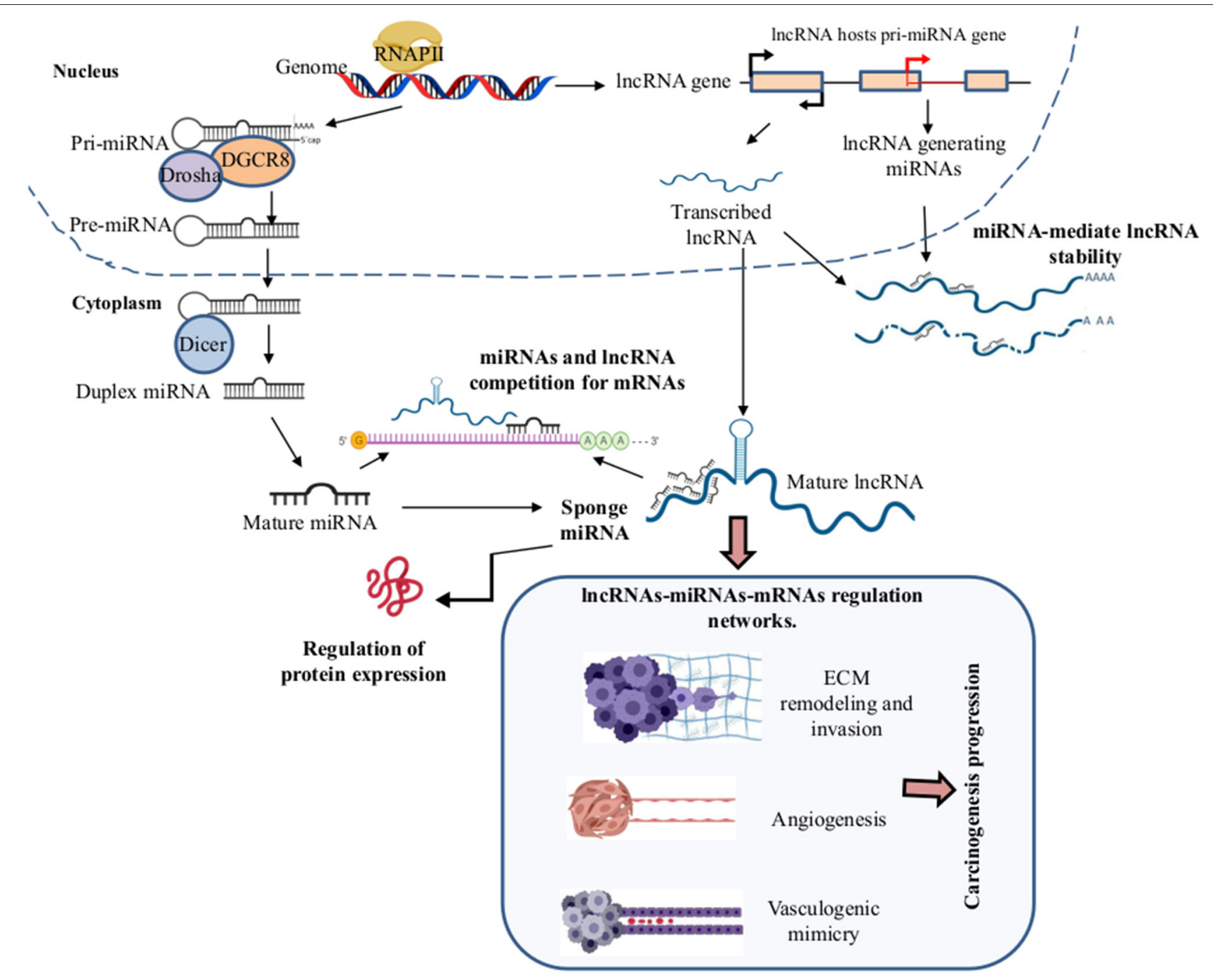

FIGURE 3 | Long non-coding RNAs (IncRNAlncRNAs)-microRNAs (miRNAs)-mRNAs regulation networks in the VM development. During the biogenesis of the miRNAs and IncRNAs in the nucleus by the RNAPII, the pri-miRNA and IncRNAs are exported to the cytoplasm where the mature miRNAs and IncRNAs are formed, respectively. In the cytoplasm, LncRNAs can function as sponges of miRNAs by competition for the binding to mRNA target genes, leading to the formation of complex regulatory networks of IncRNAs-miRNAs-mRNAs, promoting angiogenesis, extracellular matrix (ECM) remodeling, invasion, migration, EMT, metastasis, and VM formation in solid tumors. Created with Biorender.com.

(104, 105). This network promotes the acquisition of cellular phenotypes such as migration, invasion, angiogenesis, and VM (Figure 3). lcRNAs are involved in a wide range of cellular processes regulating gene expression through multiple molecular mechanisms such as mRNA degradation and regulation of protein activity; scaffolds in the assembly of complexes, guides, decoys, or riborepressors; riboactivators; translational inhibition; chromatin remodeling; and miRNAs sponging (106). LncRNAs decrease miRNA target concentration within the cell through of their specific binding, which inhibits their function. Interestingly, hypoxia induces the expression of many lncRNAs and, similarly to miRNAs, lncRNAs are differentially expressed in diverse tumors leading to cancer hallmarks like metastasis via VM formation (107) (Figure 4).
For instance, Guo et al. compared the differential expression of lncRNAs in metastatic tissue, primary gastric cancer, and normal gastric tissue. High expression of the lncRNA olfactory receptor [family 3, subfamily A, member 4 (OR3A4)] is associated with gastric cancer metastasis, but in gastric cancer, this is related to clinicopathological features. This lncRNAs promotes cell proliferation, migration, and invasion in gastric cancer. The in vitro assays of OR3A4 cells induced VM and tubule formation in HUVECs cells. The high expression in cell lines induced angiogenesis in chicken embryos mediated by VEGF-C and MMP-9. This promotes the activation of target genes PDLIM2, MACC1, NTN4, and GNB2L1. Furthermore, high expression of OR3A4 has been observed in different types of cancer like esophageal, gastric, colon, gallbladder, pancreatic, hepatic, and 


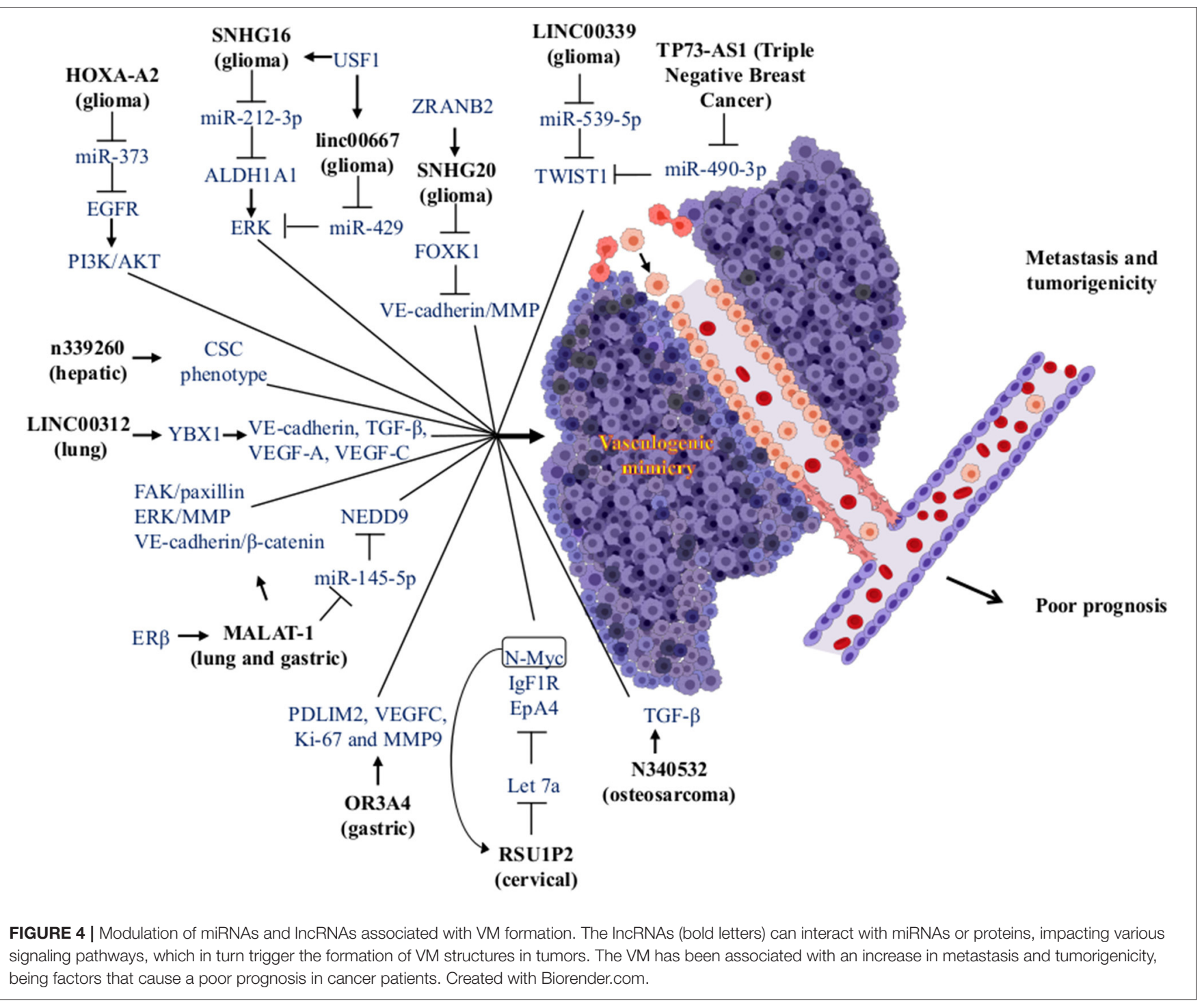

several gastric cancer cell lines (SNU-16, AGS, SNU-1, KATOIII, MKN45, NCI-N87, and SGC7901) and one immortalized gastric mucosa cell line (GES-1) (108). In another report, gastric cancer was detected via the overexpression of the lncRNA metastasisassociated lung adenocarcinoma transcript 1 (MALAT-1). MALAT-1 is associated with poor prognosis, endothelial vessels formation, and VM. Its overexpression increased migration, invasion, vascular permeability, and tumorigenicity in a nude mice model. Also, MALAT-1 regulates angiogenesis and VM through modulation of VE-cadherin/ $\beta$-catenin complex, ERK/MMP, and FAK/Paxillin signaling pathways (109).

In cervical cancer, high expression of the lncRNA Ras suppressor protein 1 pseudogene 2 (RSU1P2) was associated with VM formation. Its overexpression reduces apoptosis, cell cycle progression, and the EMT in nude mice-induced tumorigenesis. This increases the cell viability, proliferation, migration, invasion, and VM. The lncRNA and miR-let-7a compete for binding sites for IGF1R, N-myc, and EphA4, which inhibits their suppressive effect. Interestingly, high expression of $\mathrm{N}$-myc induced the overexpression of RSU1P2 and decreased the expression of let-7a forming a positive feedback loop (110).

In glioma tissues and glioma cell lines, the lncRNA LINC00339 was correlated with VM formation by its up-regulation. Knockdown of LINC00339 decreases cell proliferation, migration, and invasion, and led to the development of VM. There is also increased survival via reduction of tumor growth through interactions with miR-539$5 \mathrm{p}$. This system in turn increased the expression of TWIST1 that binds to promoters of MMP-2 and MMP-14 stimulating its transcription (111). Furthermore, the lncRNAHOXA cluster antisense RNA 2 (HOXA-AS2) was overexpressed in tissues and cell lines of glioma correlating with cell viability, migration, invasion, and VM formation via negative regulation of miR-373 and EGFR over-expression. EGFR enhances the expression levels of VE-cadherin as well as the activity of MMP-2 and MMP-9 
metalloproteases in U87 and U251 cell lines. This favors VM development through activation of the PI3K/AKT signaling pathway (112).

Another report in gliomas found high expression of upstream transcription factor 1 and aldehyde dehydrogenase-1. These promoted cell proliferation, migration, invasion, and VM development. These molecules were related to histopathological grading. This kind of tumor has high expression of lncRNAs SNHG16 and linc00667 that induce the VM regulating of upstream transcription factor 1 and aldehyde dehydrogenase- 1 targets, which are regulated by miR-212-3p and miR-429 and have low expression in gliomas. The inhibition of SNHG16 and linc00667 caused overexpression of miR-212-3p and miR-429 and the inhibition of VM (113).

In lung cancer, the estrogen receptor $\beta$ interacts with different estrogen response elements located in the lncRNA MALAT-1 promoter to increase the expression. Upregulation of MALAT-1 decreases the expression of miR-145-5p and increases overexpression of the NEDD oncogene (a target of miR-145$5 \mathrm{p}$ and linked to non-small cell lung cancer metastasis). This promotes VM formation and cell invasion in vitro and in vivo (114).

$\mathrm{Li}$ et al. reported the high expression of the lncRNA small nucleolar RNA host gene 7 (SNHG7) in colorectal cancer. SNHG7 is involved in cancer progression with poor prognosis and increased cell proliferation (in vitro and in vivo), cell cycle progression, migration, invasion, and VM formation. It blocks apoptosis in cell lines. They showed that miR-34a is a direct target of SNHG7. It regulates the expression of the GalNAc transferase 7 (GALNT7). Thus, SNHG7 could increase the expression level of GALNT7 oncogene by sponging miR-34a. They also demonstrated that SNHG7, miR-34a, and GALNT7 can increase the activity of the PI3K/AKT/mTOR pathway in colorectal cancer cell lines with different metastatic degrees (115). In triple-negative breast cancer, the high IncRNAs expression TP73 antisense RNA 1 (TP73-AS1) was associated with VM. Besides, TP73-AS1 was overexpressed in MDA-MB-231 cells and binds specifically to miR-490-3p. Furthermore, miR-490$3 p$ is regulated by TP73-AS1 inducing an increase in the TWIST1 (target of miR-490-3p) expression and promoting the development VM (116).

LncRNAs are regulated by various RNA-binding proteins. $\mathrm{Li}$ et al. demonstrated that the zinc-finger RAN-binding domain-containing protein 2 (ZRANB2) is one RNA-binding protein that is overexpressed in tissues and cell lines of glioma. Due to protein-RNA interactions, ZRANB2 stabilizes the SNHG20 lncRNA, promotes the degradation of Forkhead box K1 (FOXK1), and increases the transcription of MMP1, MMP-9, and VE-cadherin; this stimulates proliferation, migration, invasion, and VM development in this type of cancer (117).

In HCC, high expression of n339260 lncRNA was related to the expression of stem cell markers (c-myc, sox2, and Nanog) as well as with high expression of VE-cadherin, VM formation, metastasis, poor prognosis, and low survival of the patients. Therefore, this lncRNA can induce VM through a CSC phenotype (118).
Another lncRNA related to the development of VM in lung cancer is LINC00312. Its high expression was observed in metastatic lung adenocarcinoma patients and is associated with poor survival. Overexpression of LINC00312 in mice increase the number of metastatic tumor nodules by increasing migration, invasion, and stimulation of VM. LINC00312 mediates the aforementioned effects through direct binding to the transcription factor Y-Box Binding Protein 1 (YBX1), which induces the expression of angiogenic genes such as VE-cadherin, TGF- $\beta$, VEGF-A, and VEGF-C (119).

In osteosarcoma, Ren et al. reported that lncRNAs and mRNAs are differentially expressed and are associated with VM in the extremely aggressive 143B osteosarcoma cell line. They found that IncRNA n340532 that is silenced in 143B cells by siRNA reduces the VM formation in vitro. Nude mice were injected with n340532-knockdown in 143B cells and develop smaller tumors with fewer metastatic nodules and VM channels vs. control mice (120).

These few studies show that lncRNAs-miRNAs-mRNAs play critical roles in the regulation of VM development. They have clinical implications in several types of highly aggressive cancer because they are involved with tumor progression, poor survival and prognosis, resistance to therapy, and tumor recurrence. Thus, some miRNAs and lncRNAs have been proposed as prognostic and diagnostic biomarkers in solid tumors, although the mechanisms of interaction between lncRNAs-miRNAsmRNAs have not been completely elucidated yet. A study of these interactions can better explain these regulatory networks and can explain how the cell coordinates complex events during VM. The data can also better explain the clinicopathological relationships in the development of tumors.

\section{CONCLUSION AND PERSPECTIVES}

This review provides the most recent evidence on the impact of $\mathrm{VM}$ as an alternative way of generating blood vessels in tumors. The tumor microenvironment exerts a clonal selection pressure on the tumor cells to adapt to the microenvironment with low oxygen pressure and acidic/hypoxic environments. These changes promote the formation of VM in solid tumors where HIF-1 $\alpha$ is the protagonist modulating different molecules such as VE-cadherin, EphA2, LN5 $\gamma 2$, MMPs, VEGF, STAT3, Bcl2 , and signaling pathways as TGF- $\beta 1$, EGFR/PI3K/AKT, and RhoA/ROC. With all these antecedents, HIF- $1 \alpha$ is considered a master regulator that promotes MV.

During EMT, the structure of the cytoskeleton of the tumor cell undergoes changes that contribute to the plasticity of the tumor; it mimics the characteristics of ECs, which help migration, invasion, and metastasis of cells. In this context, it is necessary to understand the mechanism of the EMT process and the relationship that exists with the VM because these events provide properties to the tumor cells that make the anti-angiogenic therapies inefficient. In addition, we can identify therapeutic targets that contribute to the treatment of the most frequent solid tumors that usually respond to the start of therapy and subsequently relapse and do not 
respond to treatment. Examples include small cell lung cancer, pancreatic, osteosarcomas, melanomas, and sarcomas. Different miRNAs and lncRNAs may inhibit VM; they could be critical to the design of new therapeutic strategies. Nevertheless, the contribution of lncRNAs in VM remains largely unknown, few miRNAs and lncRNAs have been functionally studied in detail, and many important questions remain to be addressed. With the development of new and powerful genomic technologies, particularly next-generation sequencing, several lncRNAs can be identified in the future. These would be associated with different cancer types for their use in clinical practice.

\section{AUTHOR CONTRIBUTIONS}

ÁC-R, OH, and JL-G organized the entire manuscript, wrote the $\mathrm{draft}$, and revised the last version of manuscript. ÁC-R, RG-V, and CL-C wrote the Mechanisms of VM in Human Cancers and

\section{REFERENCES}

1. Cao Z, Shang B, Zhang G, Miele L, Sarkar FH, Wang Z, et al. Tumor cell-mediated neovascularization and lymphangiogenesis contrive tumor progression and cancer metastasis. Biochim Biophys Acta. (2013) 1836:27386. doi: 10.1016/j.bbcan.2013.08.001

2. Furuya M, Nishiyama M, Kasuya Y, Kimura S, Ishikura H. Pathophysiology of tumor neovascularization. Vasc Health Risk Manag. (2005) 1:277-90. doi: $10.2147 /$ vhrm.2005.1.4.277

3. Katayama Y, Uchino J, Chihara Y, Tamiya N, Kaneko Y, Yamada T, et al. Tumor neovascularization and developments in therapeutics. Cancers. (2019) 11:316. doi: 10.3390/cancers11030316

4. Delgado-Bellido D, Serrano-Saenz S, Fernandez-Cortes M, Oliver FJ. Vasculogenic mimicry signaling revisited: focus on non-vascular VEcadherin. Mol Cancer. (2017) 16:65. doi: 10.1186/s12943-017-0631-x

5. Kirschmann DA, Seftor EA, Hardy KM, Seftor RE, Hendrix MJ. Molecular pathways:vasculogenic mimicry in tumor cells:diagnostic and therapeutic implications. Clin Cancer Res. (2012) 18:2726-32. doi: 10.1158/1078-0432.CCR-11-3237

6. Fukumura D, Duda DG, Munn LL, Jain RK. Tumor microvasculature and microenvironment: novel insights through intravital imaging in pre-clinical models. Microcirculation. (2010) 17:206-25. doi: 10.1111/j.1549-8719.2010.00029.x

7. Fukumura D, Jain RK. Tumor microvasculature and microenvironment:targets for anti-angiogenesis and normalization. Microvasc Res. (2007) 74:72-84. doi: 10.1016/j.mvr.2007.05.003

8. Schaaf MB, Garg AD, Agostinis P. Defining the role of the tumor vasculature in antitumor immunity and immunotherapy. Cell Death Dis. (2018) 9:115. doi: 10.1038/s41419-017-0061-0

9. Cao M-x, Jiang Y-p, Tang Y-l, Liang X-h. The crosstalk between lncRNA and microRNA in cancer metastasis: orchestrating the epithelial-mesenchymal plasticity. Oncotarget. (2017) 8:12472-83. doi: 10.18632/oncotarget.13957

10. Petrova V, Annicchiarico-Petruzzelli M, Melino G, Amelio I. The hypoxic tumour microenvironment. Oncogenesis. (2018) 7:1-13. doi: 10.1038/s41389-017-0011-9

11. Wang M, Zhao J, Zhang L, Wei F, Lian Y, Wu Y, et al. Role of tumor microenvironment in tumorigenesis. J Cancer. (2017) 8:761-73. doi: $10.7150 /$ jca. 17648

12. Estrella V, Chen T, Lloyd M, Wojtkowiak J, Cornnell HH, Ibrahim-Hashim A, et al. Acidity generated by the tumor microenvironment drives local invasion. Cancer Res. (2013) 73:1524-35. doi: 10.1158/0008-5472.CAN-12-2796

13. Stock C, Pedersen SF. Roles of $\mathrm{pH}$ and the $\mathrm{Na}^{+} / \mathrm{H}^{+}$exchanger NHE1 in cancer: from cell biology and animal models to an
CSCs and VM sections. YS-V, DA-C, and MM-L wrote the Role of Tumor Microenvironment and the EMT in the Development of VM section. MM-L, JL-G, and DA-C wrote the section on the role of EMT in VM and wrote the section on the role of miRNAs and signaling pathway in vasculogenic mimicry in solid tumors and modulation of EMT-VM by miRNAs. YS-V, RG-V, CL-C, OH, JL-G, and CL-C wrote the section on the MiRNAs and $\operatorname{lncRNAs}$ and the regulation networks by lncRNAs-miRNAs and their clinical relation to the VM. Figures 1-4 and Tables 1, 2 were designed and made by ÁC-R, MM-L, YS-V, and OH.

\section{ACKNOWLEDGMENTS}

The authors thank Instituto Nacional de Enfermedades Respiratorias Ismael Cosio Villegas, Universidad Autónoma de la Ciudad de México, and Universidad Autónoma Metropolitana Unidad Xochimilco. emerging translational perspective? Semin Cancer Biol. (2017) 43:5-16. doi: 10.1016/j.semcancer.2016.12.001

14. Maniotis AJ, Folberg R, Hess A, Seftor EA, Gardner LM, Pe'er J, et al. Vascular channel formation by human melanoma cells in vivo and in vitro: vasculogenic mimicry. Am J Pathol. (1999) 155:739-52. doi: 10.1016/S0002-9440(10)65173-5

15. Sun B, Zhang D, Zhao N, Zhao X. Epithelial-to-endothelial transition and cancer stem cells: two cornerstones of vasculogenic mimicry in malignant tumors. Oncotarget. (2017) 8:30502-10. doi: 10.18632/oncotarget.8461

16. Cao Z, Sun B, Zhao X, Zhang Y, Gu Q, Liang X, et al. The expression and functional significance of runx2 in hepatocellular carcinoma: its role in vasculogenic mimicry and epithelial-mesenchymal transition. Int J Mol Sci. (2017) 18:E500. doi: 10.3390/ijms18030500

17. Song $\mathrm{H}, \mathrm{Ci} \mathrm{H}, \mathrm{Xu} J$, Xu Z, Zhang Y, Wang Y, et al. Vasculogenic mimicry and expression of slug and vimentin correlate with metastasis and prognosis in non-small cell lung cancer. Int J Clin Exp Pathol. (2018) 11:2749-58.

18. Sun D, Sun B, Liu T, Zhao X, Che N, Gu Q, et al. Slug promoted vasculogenic mimicry in hepatocellular carcinoma. J Cell Mol Med. (2013) 17:1038-47. doi: $10.1111 /$ jcmm. 12087

19. Han C, Sun B, Zhao X, Zhang Y, Gu Q, Liu F, et al. Phosphorylation of STAT3 promotes vasculogenic mimicry by inducing epithelial-to-mesenchymal transition in colorectal cancer. Technol Cancer Res Treat. (2017) 16:1209-19. doi: $10.1177 / 1533034617742312$

20. Zhou X, Gu R, Han X, Wu G, Liu J. Cyclin-dependent kinase 5 controls vasculogenic mimicry formation in non-small cell lung cancer via the FAKAKT signaling pathway. Biochem Biophys Res Commun. (2017) 492:447-52. doi: 10.1016/j.bbrc.2017.08.076

21. Du J, Sun B, Zhao X, Gu Q, Dong X, Mo J, et al. Hypoxia promotes vasculogenic mimicry formation by inducing epithelial-mesenchymal transition in ovarian carcinoma. Gynecol Oncol. (2014) 133:575-83. doi: 10.1016/j.ygyno.2014.02.034

22. Li W, Zong S, Shi Q, Li H, Xu J, Hou F. Hypoxia-induced vasculogenic mimicry formation in human colorectal cancer cells: involvement of HIF1a, Claudin-4, and E-cadherin and Vimentin. Sci Rep. (2016) 6:37534. doi: $10.1038 /$ srep37534

23. Wang M, Zhao X, Zhu D, Liu T, Liang X, Liu F, et al. HIF-1 $\alpha$ promoted vasculogenic mimicry formation in hepatocellular carcinoma through LOXL2 up-regulation in hypoxic tumor microenvironment. J Exp Clin Cancer Res. (2017) 36:60. doi: 10.1186/s13046-017-0533-1

24. Yang J, Zhu D-M, Zhou X-G, Yin N, Zhang Y, Zhang Z-X, et al. HIF$2 \alpha$ promotes the formation of vasculogenic mimicry in pancreatic cancer by regulating the binding of Twist1 to the VE-cadherin promoter. Oncotarget. (2017) 8:47801-15. doi: 10.18632/oncotarget. 17999 
25. Liu Z, Sun B, Qi L, Li H, Gao J, Leng X. Zinc finger E-box binding homeobox 1 promotes vasculogenic mimicry in colorectal cancer through induction of epithelial-to-mesenchymal transition. Cancer Sci. (2012) 103:813-20. doi: 10.1111/j.1349-7006.2011.02199.x

26. Wang H, Huang B, Li BM, Cao KY, Mo CQ, Jiang SJ, et al. ZEB1-mediated vasculogenic mimicry formation associates with epithelial-mesenchymal transition and cancer stem cell phenotypes in prostate cancer. J Cell Mol Med. (2018) 22:3768-81. doi: $10.1111 / \mathrm{jcmm} .13637$

27. Yang $\mathrm{Z}$, Sun $\mathrm{B}$, Li $\mathrm{Y}$, Zhao $\mathrm{X}$, Zhao $\mathrm{X}, \mathrm{Gu}$ Q, et al. ZEB2 promotes vasculogenic mimicry by TGF- $\beta 1$ induced epithelial-to-mesenchymal transition in hepatocellular carcinoma. Exp Mol Pathol. (2015) 98:352-9. doi: 10.1016/j.yexmp.2015.03.030

28. Li Y, Sun B, Zhao X, Zhang D, Wang X, Zhu D, et al. Subpopulations of $\mathrm{uPAR}+$ contribute to vasculogenic mimicry and metastasis in large cell lung cancer. Expe Mol Pathol. (2015) 98:136-44. doi: 10.1016/j.yexmp.2015.02.001

29. Ou H, Chen Z, Xiang L, Fang Y, Xu Y, Liu Q, et al. Frizzled 2-induced epithelial-mesenchymal transition correlates with vasculogenic mimicry, stemness, and Hippo signaling in hepatocellular carcinoma. Cancer Sci. (2019) 110:1169-82. doi: 10.1111/cas.13949

30. Jue C, Lin C, Zhisheng Z, Yayun Q, Feng J, Min Z, et al. Notch1 promotes vasculogenic mimicry in hepatocellular carcinoma by inducing EMT signaling. Oncotarget. (2017) 8:2501-13. doi: 10.18632/oncotarget.12388

31. Yao L, Zhang D, Zhao X, Sun B, Liu Y, Gu Q, et al. Dickkopf-1-promoted vasculogenic mimicry in non-small cell lung cancer is associated with EMT and development of a cancer stem-like cell phenotype. J Cell Mol Med. (2016) 20:1673-85. doi: 10.1111/jcmm.12862

32. Zhang X, Cui P, Ding B, Guo Y, Han K, Li J, et al. Netrin-1 elicits metastatic potential of non-small cell lung carcinoma cell by enhancing cell invasion, migration and vasculogenic mimicry via EMT induction. Cancer Gene Ther. (2018) 25:18-26. doi: 10.1038/s41417-017-0008-8

33. Wang W, Lin P, Sun B, Zhang S, Cai W, Han C, et al. Epithelialmesenchymal transition regulated by EphA2 contributes to vasculogenic mimicry formation of head and neck squamous cell carcinoma. BioMed Res Int. (2014) 2014:803914. doi: 10.1155/2014/803914

34. Li W, Zhou Y. LRIG1 acts as a critical regulator of melanoma cell invasion, migration, and vasculogenic mimicry upon hypoxia by regulating EGFR/ERK-triggered epithelial-mesenchymal transition. Biosci Rep. (2019) 39:BSR20181165. doi: 10.1042/BSR20181165

35. Guo X, Xu S, Gao X, Wang J, Xue H, Chen Z, et al. Macrophage migration inhibitory factor promotes vasculogenic mimicry formation induced by hypoxia via CXCR4/AKT/EMT pathway in human glioblastoma cells. Oncotarget. (2017) 8:80358-72. doi: 10.18632/oncotarget.18673

36. Sun T, Sun BC, Zhao XL, Zhao N, Dong XY, Che N, et al. Promotion of tumor cell metastasis and vasculogenic mimicry by way of transcription coactivation by Bcl-2 and Twist1: a study of hepatocellular carcinoma. Hepatology. (2011) 54:1690-706. doi: 10.1002/hep.24543

37. Sun T, Zhao N, Zhao XL, Gu Q, Zhang SW, Che N, et al. Expression and functional significance of Twist1 in hepatocellular carcinoma: its role in vasculogenic mimicry. Hepatology. (2010) 51:545-56. doi: 10.1002/hep. 23311

38. Wang L, Lin L, Chen X, Sun L, Liao Y, Huang N, et al. Metastasisassociated in colon cancer-1 promotes vasculogenic mimicry in gastric cancer by upregulating TWIST1/2. Oncotarget. (2015) 6:11492-506. doi: 10.18632/oncotarget.3416

39. Qi H, Sun B, Zhao X, Du J, Gu Q, Liu Y, et al. Wnt5a promotes vasculogenic mimicry and epithelial-mesenchymal transition via protein kinase $\mathrm{C} \alpha$ in epithelial ovarian cancer. Oncol Rep. (2014) 32:771-9. doi: 10.3892/or.2014.3229

40. Sun J, Sun B, Sun R, Zhu D, Zhao X, Zhang Y, et al. HMGA2 promotes vasculogenic mimicry and tumor aggressiveness by upregulating Twist1 in gastric carcinoma. Sci Rep. (2017) 7:2229. doi: 10.1038/s41598-017-02494-6

41. Zhang J-G, Li X-Y, Wang Y-Z, Zhang Q-D, Gu S-Y, Wu X, et al. ROCK is involved in vasculogenic mimicry formation in hepatocellular carcinoma cell line. PLoS ONE. (2014) 9:e107661. doi: 10.1371/journal.pone.0107661

42. Xia Y, Cai XY, Fan JQ, Zhang LL, Ren JH, Li ZY, et al. The role of sema4D in vasculogenic mimicry formation in non-small cell lung cancer and the underlying mechanisms. Int J Cancer. (2019) 144:2227-38. doi: $10.1002 /$ ijc. 31958
43. Sun B, Zhang D, Zhang S, Zhang W, Guo H, Zhao X. Hypoxia influences vasculogenic mimicry channel formation and tumor invasionrelated protein expression in melanoma. Cancer Lett. (2007) 249:188-97. doi: 10.1016/j.canlet.2006.08.016

44. Zhao N, Sun B-C, Sun T, Ma Y-M, Zhao X-L, Liu Z-Y, et al. Hypoxia-induced vasculogenic mimicry formation via VE-cadherin regulation by Bcl-2. Med Oncol. (2012) 29:3599-607. doi: 10.1007/s12032-012-0245-5

45. Gao S, Fan C, Huang H, Zhu C, Su M, Zhang Y. Effects of HCG on human epithelial ovarian cancer vasculogenic mimicry formation in vivo. Oncol Lett. (2016) 12:459-66. doi: 10.3892/ol.2016.4630

46. Su M, Wei W, Xu X, Wang X, Chen C, Su L, et al. Role of hCG in vasculogenic mimicry in OVCAR-3 ovarian cancer cell line. Int J Gynecol Cancer. (2011) 21:1366-74. doi: 10.1097/IGC.0b013e31822c7529

47. Su M, Xu X, Wei W, Gao S, Wang X, Chen C, et al. Involvement of human chorionic gonadotropin in regulating vasculogenic mimicry and hypoxiainducible factor-1 $\alpha$ expression in ovarian cancer cells. Cancer Cell Int. (2016) 16:50. doi: 10.1186/s12935-016-0327-0

48. Li S, Zhang Q, Zhou L, Guan Y, Chen S, Zhang Y, et al. Inhibitory effects of compound DMBT on hypoxia-induced vasculogenic mimicry in human breast cancer. Biomed Pharmacother. (2017) 96:982-92. doi: 10.1016/j.biopha.2017.11.137

49. Jin-lu M, Su-xia H, Qing Z, Jing Z, Dan Z, Li W, et al. (2011). Role of twist in vasculogenic mimicry formation in hypoxic hepatocellular carcinoma cells in vitro. Biochem Biophys Res Commun. 408:686-91. doi: 10.1016/j.bbrc.2011.04.089

50. Liu K, Sun B, Zhao X, Wang X, Li Y, Qiu Z, et al. Hypoxia induced epithelial-mesenchymal transition and vasculogenic mimicry formation by promoting Bcl-2/Twist1 cooperation. Exp Mol Pathol. (2015) 99:383-91. doi: 10.1016/j.yexmp.2015.08.009

51. Liu K, Sun B, Zhao X, Wang X, Li Y, Qiu Z, et al. Hypoxia promotes vasculogenic mimicry formation by the Twist1-Bmil connection in hepatocellular carcinoma. Int J Mol Med. (2015) 36:783-91. doi: $10.3892 / \mathrm{ijmm} .2015 .2293$

52. Zhang X, Song Q, Wei C, Qu J. LRIG1 inhibits hypoxia-induced vasculogenic mimicry formation via suppression of the EGFR/PI3K/AKT pathway and epithelial-to-mesenchymal transition in human glioma SHG-44 cells. Cell Stress Chaperones. (2015) 20:631-41. doi: 10.1007/s12192-015-0587-y

53. Wang H-F, Wang S-S, Zheng M, Dai L-L, Wang K, Gao, X-L, et al. Hypoxia promotes vasculogenic mimicry formation by vascular endothelial growth factor A mediating epithelial-mesenchymal transition in salivary adenoid cystic carcinoma. Cell Prolif. (2019) 52:e12600. doi: 10.1111/cpr.12600

54. Song YY, Sun LD, Liu ML, Liu ZL, Chen F, Zhang YZ, et al. STAT3, p-STAT3 and HIF- $1 \alpha$ are associated with vasculogenic mimicry and impact on survival in gastric adenocarcinoma. Oncol Lett. (2014) 8:431-7. doi: 10.3892/ol.2014.2059

55. Tang N-N, Zhu H, Zhang H-J, Zhang W-F, Jin H-L, Wang L, et al. HIF$1 \alpha$ induces VE-cadherin expression and modulates vasculogenic mimicry in esophageal carcinoma cells. World J Gastroenterol. (2014) 20:17894-904. doi: $10.3748 /$ wjg.v20.i47.17894

56. Wykosky J, Debinski W. The EphA2 receptor and ephrinA1 ligand in solid tumors:function and therapeutic targeting. Mol Cancer Res. (2008) 6:1795-806. doi: 10.1158/1541-7786.MCR-08-0244

57. Hess AR, Seftor EA, Gardner LM, Carles-Kinch K, Schneider GB, Seftor RE, et al. Molecular regulation of tumor cell vasculogenic mimicry by tyrosine phosphorylation: role of epithelial cell kinase (Eck/EphA2). Cancer Res. (2001) 61:3250-5.

58. Wang H, Lin H, Pan J, Mo C, Zhang F, Huang B, et al. Vasculogenic mimicry in prostate cancer: the roles of EphA2 and PI3K. J Cancer. (2016) 7:1114-24. doi: $10.7150 /$ jca. 14120

59. Yeo C, Lee H-J, Lee E-O. Serum promotes vasculogenic mimicry through the EphA2/VE-cadherin/AKT pathway in PC-3 human prostate cancer cells. Life Sci. (2019) 221:267-73. doi: 10.1016/j.lfs.2019.02.043

60. Liang X, Sun R, Zhao X, Zhang Y, Gu Q, Dong X, et al. Rictor regulates the vasculogenic mimicry of melanoma via the AKT-MMP2/9 pathway. J Cell Mol Med. (2017) 21:3579-91. doi: 10.1111/jcmm. 13268

61. Bissanum R, Lirdprapamongkol K, Svasti J, Navakanitworakul R, Kanokwiroon K. The role of WT1 isoforms in vasculogenic mimicry and 
metastatic potential of human triple negative breast cancer cells. Biochem Biophys Res Commun. (2017) 494:256-62. doi: 10.1016/j.bbrc.2017.10.043

62. Lu X-S, Sun W, Ge C-Y, Zhang W-Z, Fan Y-Z. Contribution of the PI3K/MMPs/Ln-5 $\gamma 2$ and EphA2/FAK/Paxillin signaling pathways to tumor growth and vasculogenic mimicry of gallbladder carcinomas. Int $J$ Oncol. (2013) 42:2103-15. doi: 10.3892/ijo.2013.1897

63. Vestweber D. VE-cadherin:the major endothelial adhesion molecule controlling cellular junctions and blood vessel formation. Arterioscler Thromb Vasc Biol. (2008) 28:223-32. doi: 10.1161/ATVBAHA.107.158014

64. Delgado-Bellido D, Fernández-Cortés M, Rodríguez MI, Serrano-Sáenz S, Carracedo A, Garcia-Diaz A, et al. VE-cadherin promotes vasculogenic mimicry by modulating kaiso-dependent gene expression. Cell Death Differ. (2019) 26:348-61. doi: 10.1038/s41418-018-0125-4

65. Lin X, Sun R, Zhao X, Zhu D, Zhao X, Gu Q, et al. C-myc overexpression drives melanoma metastasis by promoting vasculogenic mimicry via c-myc/snail/Bax signaling. J Mol Med. (2017) 95:53-67. doi: 10.1007/s00109-016-1452-x

66. Liu T, Sun B, Zhao X, Gu Q, Dong X, Yao Z, et al. HER2/neu expression correlates with vasculogenic mimicry in invasive breast carcinoma. J Cell Mol Med. (2013) 17:116-22. doi: 10.1111/j.1582-4934.2012.01653.x

67. Cooper J, Giancotti FG. Integrin signaling in cancer:mechanotransduction, stemness, epithelial plasticity, and therapeutic resistance. Cancer Cell. (2019) 35:347-67. doi: 10.1016/j.ccell.2019.01.007

68. Liu Y, Li F, Yang YT, Xu XD, Chen JS, Chen TL, et al. IGFBP2 promotes vasculogenic mimicry formation via regulating CD144 and MMP2 expression in glioma. Oncogene. (2019) 38:1815-31. doi: 10.1038/s41388-018-0525-4

69. Rong X, Huang B, Qiu S, Li X, He L, Peng Y. Tumor-associated macrophages induce vasculogenic mimicry of glioblastoma multiforme through cyclooxygenase-2 activation. Oncotarget. (2016) 7:83976-86. doi: 10.18632 /oncotarget.6930

70. Basu GD, Liang WS, Stephan DA, Wegener LT, Conley CR, Pockaj BA, et al. A novel role for cyclooxygenase-2 in regulating vascular channel formation by human breast cancer cells. Breast Cancer Res. (2006) 8:R69. doi: $10.1186 /$ bcr1626

71. Oladipupo SS, Kabir AU, Smith C, Choi K, Ornitz DM. Impaired tumor growth and angiogenesis in mice heterozygous for Vegfr2 (Flk1). Sci Rep. (2018) 8:14724. doi: 10.1038/s41598-018-33037-2

72. Yao X, Ping Y, Liu Y, Chen K, Yoshimura T, Liu M, et al. Vascular Endothelial Growth Factor Receptor 2 (VEGFR-2) plays a key role in vasculogenic mimicry formation, neovascularization and tumor initiation by glioma stem-like cells. PLoS ONE. (2013) 8:e57188. doi: 10.1371/annotation/aed5b555-b826-4591-8aa6-284ad888627d

73. Francescone R, Scully S, Bentley B, Yan W, Taylor SL, Oh D, et al. Glioblastoma-derived tumor cells induce vasculogenic mimicry through Flk-1 protein activation. J Biol Chem. (2012) 287:24821-31. doi: $10.1074 /$ jbc.M111.334540

74. Thomas P, Pranatharthi A, Ross C, Srivastava S. RhoC: a fascinating journey from a cytoskeletal organizer to a cancer stem cell therapeutic target. J Exp Clin Cancer Res. (2019) 38:328. doi: 10.1186/s13046-019-1327-4

75. Zhang J-G, Zhang D-D, Liu Y, Hu J-N, Zhang X, Li L, et al. RhoC/ROCK2 promotes vasculogenic mimicry formation primarily through ERK/MMPs in hepatocellular carcinoma. Biochim Biophys Acta Mol Basis Dis. (2019) 1865:1113-25. doi: 10.1016/j.bbadis.2018.12.007

76. Yao X-h, Ping Y-f, Bian X-w. Contribution of cancer stem cells to tumor vasculogenic mimicry. Protein Cell. (2011) 2:266-72. doi: 10.1007/s13238-011-1041-2

77. Qi L, Song W, Liu Z, Zhao X, Cao W, Sun B. Wnt3a promotes the vasculogenic mimicry formation of colon cancer via wnt $/ \beta$-catenin signaling. Int J Mol Sci. (2015) 16:18564-79. doi: 10.3390/ijms160818564

78. Larson AR, Lee C-W, Lezcano C, Zhan Q, Huang J, Fischer AH, et al. Melanoma spheroid formation involves laminin-associated vasculogenic mimicry. Am J Pathol. (2014) 184:71-8. doi: 10.1016/j.ajpath.2013.09.020

79. MacFarlane L-A, Murphy, PR. MicroRNA: biogenesis, function and role in cancer. Curr Genomics. (2010) 11:537-61. doi: 10.2174/138920210793175895

80. Bertoli G, Cava C, Castiglioni I. MicroRNAs: new biomarkers for diagnosis, prognosis, therapy prediction and therapeutic tools for breast cancer. Theranostics. (2015) 5:1122-43. doi: 10.7150/thno.11543
81. Bai J, Yeh S, Qiu X, Hu L, Zeng J, Cai Y, et al. TR4 nuclear receptor promotes clear cell renal cell carcinoma (ccRCC) vasculogenic mimicry (VM) formation and metastasis via altering the miR490-3p/vimentin signals. Oncogene. (2018) 37:5901-12. doi: 10.1038/s41388-018-0269-1

82. Langer EM, Kendsersky ND, Daniel CJ, Kuziel GM, Pelz C, Murphy KM, et al. ZEB1-repressed microRNAs inhibit autocrine signaling that promotes vascular mimicry of breast cancer cells. Oncogene. (2018) 37:1005-19. doi: $10.1038 /$ onc. 2017.356

83. Shevde LA, Metge BJ, Mitra A, Xi Y, Ju J, King JA, et al. Spheroid-forming subpopulation of breast cancer cells demonstrates vasculogenic mimicry via hsa-miR-299-5p regulated de novo expression of osteopontin. J Cell Mol Med. (2010) 14:1693-706. doi: 10.1111/j.1582-4934.2009.00821.x

84. Park Y, Kim J. Regulation of IL-6 signaling by miR-125a and let-7e in endothelial cells controls vasculogenic mimicry formation of breast cancer cells. BMB Rep. (2019) 52:214-9. doi: 10.5483/BMBRep.2019.52.3.308

85. Hulin J-A, Tommasi S, Elliot D, Hu DG, Lewis BC, Mangoni AA. MiR193b regulates breast cancer cell migration and vasculogenic mimicry by targeting dimethylarginine dimethylaminohydrolase 1. Sci Rep. (2017) 7:13996. doi: 10.1038/s41598-017-14454-1

86. Salinas-Vera YM, Marchat LA, García-Vázquez R, de la Rosa CHG, Castañeda-Saucedo E, Tito NN, et al. Cooperative multi-targeting of signaling networks by angiomiR-204 inhibits vasculogenic mimicry in breast cancer cells. Cancer Lett. (2018) 432:17-27. doi: 10.1016/j.canlet.2018.06.003

87. Wan H-Y, Li Q-Q, Zhang Y, Tian W, Li Y-N, Liu M, et al. MiR124 represses vasculogenic mimicry and cell motility by targeting amotL1 in cervical cancer cells. Cancer Lett. (2014) 355:148-58. doi: 10.1016/j.canlet.2014.09.005

88. Sun Q, Zou X, Zhang T, Shen J, Yin Y, Xiang J. The role of miR-200a in vasculogenic mimicry and its clinical significance in ovarian cancer. Gynecol Oncol. (2014) 132:730-8. doi: 10.1016/j.ygyno.2014.01.047

89. Liu W, Lv C, Zhang B, Zhou Q, Cao Z. MicroRNA-27b functions as a new inhibitor of ovarian cancer-mediated vasculogenic mimicry through suppression of VE-cadherin expression. RNA. (2017) 23:1019-27. doi: $10.1261 /$ rna. 059592.116

90. Salinas-Vera YM, Gallardo-Rincón D, García-Vázquez R, Hernándezde la Cruz ON, Marchat LA, González-Barrios JA, et al. HypoxamiRs profiling identify miR-745 as a regulator of the early stages of vasculogenic mimicry in SKOV3 ovarian cancer cells. Front Oncol. (2019) 9:381. doi: $10.3389 /$ fonc. 2019.00381

91. Song Y, Mu L, Han X, Li Q, Dong B, Li H, et al. MicroRNA9 inhibits vasculogenic mimicry of glioma cell lines by suppressing Stathmin expression. J Neurooncol. (2013) 115:381-90. doi: 10.1007/s11060-013-1245-9

92. Wu N, Zhao X, Liu M, Liu H, Yao W, Zhang Y, et al. Role of microRNA-26b in glioma development and its mediated regulation on EphA2. PLoS ONE. (2011) 6:e16264. doi: 10.1371/journal.pone.0016264

93. Xue $\mathrm{H}$, Gao X, Xu S, Zhang J, Guo X, Yan S, et al. MicroRNALet-7f reduces the vasculogenic mimicry of human glioma cells by regulating periostin-dependent migration. Oncol Rep. (2016) 35:1771-7. doi: $10.3892 /$ or. 2016.4548

94. Xu S, Zhang J, Xue H, Guo X, Han X, Li T, et al. MicroRNA-584-3p reduces the vasculogenic mimicry of human glioma cells by regulating hypoxiainduced ROCK1 dependent stress fiber formation. Neoplasma. (2017) 64:1321. doi: 10.4149/neo_2017_102

95. Li G, Huang M, Cai Y, Ke Y, Yang Y, Sun X. miR-141 inhibits glioma vasculogenic mimicry by controlling EphA2 expression. Mol Med Rep. (2018) 18:1395-404. doi: 10.3892/mmr.2018.9108

96. Zhao N, Sun B-C, Zhao X-L, Wang Y, Meng J, Che N, et al. Role of Bcl-2 and its associated miRNAs in vasculogenic mimicry of hepatocellular carcinoma. Int J Clin Exp Pathol. (2015) 8:15759-68.

97. Zhao N, Sun H, Sun B, Zhu D, Zhao X, Wang Y, et al. miR-27a-3p suppresses tumor metastasis and VM by down-regulating VE-cadherin expression and inhibiting EMT: an essential role for Twist-1 in HCC. Sci Rep. (2016) 6:23091. doi: 10.1038/srep23091

98. Yang J, Lu Y, Lin Y-Y, Zheng Z-Y, Fang J-H, He S, et al. Vascular mimicry formation is promoted by paracrine TGF- $\beta$ and SDF1 of cancer-associated fibroblasts and inhibited by miR-101 in hepatocellular carcinoma. Cancer Lett. (2016) 383:18-27. doi: 10.1016/j.canlet.2016.09.012 
99. Fang J-H, Zheng Z-Y, Liu J-Y, Xie C, Zhang Z-J, Zhuang S-M. Regulatory role of the MicroRNA-29b-IL-6 signaling in the formation of vascular mimicry. Mol Ther Nucleic Acids. (2017) 8:90-100. doi: 10.1016/j.omtn.2017. 06.009

100. Zhao X, Wang Y, Deng R, Zhang H, Dou J, Yuan H, et al. miR186 suppresses prostate cancer progression by targeting Twist1. Oncotarget. (2016) 7:3313651. doi: 10.18632/oncotarget.8887

101. Weng C, Dong H, Chen G, Zhai Y, Bai R, Hu H, et al. miR-409-3p inhibits HT1080 cell proliferation, vascularization and metastasis by targeting angiogenin. Cancer Lett. (2012) 323:171-9. doi: 10.1016/j.canlet.2012.04.010

102. Li X, Yang Z, Han Z, Wen Y, Ma Z, Wang Y. Niclosamide acts as a new inhibitor of vasculogenic mimicry in oral cancer through upregulation of miR-124 and downregulation of STAT3. Oncol Rep. (2018) 39:827-33. doi: 10.3892/or.2017.6146

103. Youness RA, Gad MZ. Long non-coding RNAs: functional regulatory players in breast cancer. Noncoding RNA Res. (2019) 4:36-44. doi: 10.1016/j.ncrna.2019.01.003

104. Zhou R-S, Zhang E-X, Sun Q-F, Ye Z-J, Liu J-W, Zhou D-H, et al. Integrated analysis of IncRNA-miRNA-mRNA ceRNA network in squamous cell carcinoma of tongue. BMC Cancer. (2019) 19:779. doi: 10.1186/s12885-019-5983-8

105. Zhou Y, Zheng X, Xu B, Hu W, Huang T, Jiang J. The identification and analysis of mRNA-lncRNA-miRNA cliques from the integrative network of ovarian cancer. Front Genet. (2019) 10:751. doi: 10.3389/fgene.2019.00751

106. Balas MM, Johnson AM. Exploring the mechanisms behind long noncoding RNAs and cancer. Noncoding RNA Res. (2018) 3:108-17. doi: 10.1016/j.ncrna.2018.03.001

107. Choudhry H, Harris AL, McIntyre A. The tumour hypoxia induced non-coding transcriptome. Mol Aspects Med. (2016) 47:35-53. doi: 10.1016/j.mam.2016.01.003

108. Guo X, Yang Z, Zhi Q, Wang D, Guo L, Li G, et al. Long noncoding RNA OR3A4 promotes metastasis and tumorigenicity in gastric cancer. Oncotarget. (2016) 7:30276-94. doi: 10.18632/oncotarget.7217

109. Li Y, Wu Z, Yuan J, Sun L, Lin L, Huang N, et al. Long non-coding RNA MALAT1 promotes gastric cancer tumorigenicity and metastasis by regulating vasculogenic mimicry and angiogenesis. Cancer Lett. (2017) 395:31-44. doi: 10.1016/j.canlet.2017.02.035

110. Liu Q, Guo X, Que S, Yang X, Fan H, Liu M, et al. LncRNA RSU1P2 contributes to tumorigenesis by acting as a ceRNA against let-7a in cervical cancer cells. Oncotarget. (2017) 8:43768-81. doi: 10.18632/oncotarget.10844

111. Guo J, Cai H, Liu X, Zheng J, Liu Y, Gong W, et al. Long non-coding RNA LINC00339 stimulates glioma Vasculogenic mimicry formation by regulating the miR-539-5p/TWIST1/MMPs axis. Mol Ther Nucleic Acids. (2018) 10:170-86. doi: 10.1016/j.omtn.2017.11.011

112. Gao Y, Yu H, Liu Y, Liu X, Zheng J, Ma J, et al. Long Non-coding RNA HOXA-AS2 regulates malignant glioma behaviors and vasculogenic mimicry formation via the MiR-373/EGFR axis. Cell Physiol Biochem. (2018) 45:13147. doi: $10.1159 / 000486253$

113. Wang D, Zheng J, Liu X, Xue Y, Liu L, Ma J, et al. Knockdown of USF1 inhibits the vasculogenic mimicry of glioma cells via stimulating SNHG16/miR-212-3p and linc00667/miR-429 axis. Mol Ther Nucleic Acids. (2019) 14:465-82. doi: 10.1016/j.omtn.2018.12.017

114. Yu W, Ding J, He M, Chen Y, Wang R, Han Z, et al. Estrogen receptor $\beta$ promotes the vasculogenic mimicry (VM) and cell invasion via altering the IncRNA-MALAT1/miR-145-5p/NEDD9 signals in lung cancer. Oncogene. (2019) 38:1225-38. doi: 10.1038/s41388-018-0463-1

115. Li Y, Zeng C, Hu J, Pan Y, Shan Y, Liu B, et al. Long non-coding RNASNHG7 acts as a target of miR-34a to increase GALNT7 level and regulate $\mathrm{PI} 3 \mathrm{~K} / \mathrm{Akt} / \mathrm{mTOR}$ pathway in colorectal cancer progression. J Hematol Oncol. (2018) 11:89. doi: 10.1186/s13045-018-0632-2

116. Tao W, Sun W, Zhu H, Zhang J. Knockdown of long non-coding RNA TP73AS1 suppresses triple negative breast cancer cell vasculogenic mimicry by targeting miR-490-3p/TWIST1 axis. Biochem Biophys Res Commun. (2018) 504:629-34. doi: 10.1016/j.bbrc.2018.08.122

117. Li X, Xue Y, Liu X, Zheng J, Shen S, Yang C, et al. ZRANB2/SNHG20/FOXK1 Axis regulates Vasculogenic mimicry formation in glioma. J Exp Clin Cancer Res. (2019) 38:68. doi: 10.1186/s13046-019-1073-7

118. Zhao X, Sun B, Liu T, Shao B, Sun R, Zhu D, et al. Long noncoding RNA n339260 promotes vasculogenic mimicry and cancer stem cell development in hepatocellular carcinoma. Cancer Sci. (2018) 109:3197-208. doi: $10.1111 /$ cas. 13740

119. Peng Z, Wang J, Shan B, Li B, Peng W, Dong Y, et al. The long noncoding RNA LINC00312 induces lung adenocarcinoma migration and vasculogenic mimicry through directly binding YBX1. Mol Cancer. (2018) 17:167. doi: 10.1186/s12943-018-0920-z

120. Ren K, Ni Y, Li X, Wang C, Chang Q, Li Y, et al. Expression profiling of long noncoding RNAs associated with vasculogenic mimicry in osteosarcoma. J Cell Biochem. (2019) 120:12473-88. doi: 10.1002/jcb. 28514

Conflict of Interest: The authors declare that the research was conducted in the absence of any commercial or financial relationships that could be construed as a potential conflict of interest.

Copyright (C) 2020 Hernández de la Cruz, López-González, García-Vázquez, SalinasVera, Muñiz-Lino, Aguilar-Cazares, López-Camarillo and Carlos-Reyes. This is an open-access article distributed under the terms of the Creative Commons Attribution License (CC BY). The use, distribution or reproduction in other forums is permitted, provided the original author(s) and the copyright owner(s) are credited and that the original publication in this journal is cited, in accordance with accepted academic practice. No use, distribution or reproduction is permitted which does not comply with these terms. 